\title{
Very low birth weight children at school age: comparison of neonatal management methods
}

\author{
E S STEINER, ELIZABETH M SANDERS, EILEEN C K PHILLIPS, C R MADDOCK
}

\section{Summary and conclusions}

The outcome of 293 infants born to a geographically defined community and weighing 501-1500 $\mathrm{g}$ was investigated. Medical intervention in the newborn period had been avoided. Morbidity was assessed at school age. Of the infants, 236 had been live born in the labour ward of this hospital; of these, $117(49.6 \%)$ died in the neonatal period, one $(0.4 \%)$ died in the first year, four $(1.7 \%)$ were untraced, $13(5.5 \%)$ had major handicap, $29(12.3 \%)$ had minor handicap, and $72(30.5 \%)$ were considered to be normal. In terms of survival, handicap, and intellectual capacity at school age the outcome compared favourably with that of infants born over the same period (1963-71) in areas where intensive methods of perinatal care were used.

These results imply that postnatal survival and potential of infants of very low birth weight are by no means prejudiced when only experienced nursing care is available.

\section{Introduction}

Obstetricians, midwives, paediatricians, and family doctors are frequently confronted with the premature delivery of babies of very low birth weight $(\leqslant 1500 \mathrm{~g})$. In a maternity unit with 3000 deliveries a year this occurs on average once a fortnight. Although more infants of very low birth weight now survive than formerly, ${ }^{1}$ some evidence suggests that handicap in survivors is little different from what it was before neonatal

\footnotetext{
Department of Paediatrics, King's Mill Hospital, Sutton-in-Ashfield E S STEINER, MB, DCH, paediatric registrar (present appointment: general practitioner, Mansfield)

C R MADDOCK, MRCPED, DA, consultant paediatrician

Nottinghamshire County Council Education Department, Schools Psychological Service

ELIZABETH M SANDERS, MA, MPHIL, senior educational psychologist EILEEN C K PHILLIPS, BA, DIPEDPSYCH, educational psychologist
}

intensive care methods were introduced in the $1950 \mathrm{~s}^{23}$ and that minimal intervention does not prejudice survival at least of the smallest infants. ${ }^{4}$ On the other hand, reports of lower mortality and rates of handicap in centres where intensive neonatal care is practised seem to carry more weight, ${ }^{56}$ and since many reports attribute the improved prognosis to advances in medical technology, skilled intervention, and a better understanding of perinatal pathophysiology, the extension of intensive care facilities for such infants is urged. ${ }^{7}{ }^{8}$ Reports of controlled trials showing long-term benefit from intensive care of babies of very low birth weight, however, are few. This is perhaps partly because belief in the benefits of intensive care methods would seem to render some trials unethical, numbers are necessarily small, and treatment programmes change so often. Regional referral centres are therefore able to compare their results only with those of previous years, those from similar centres, or national or regional statistics for the years studied.

In Mansfield in 1973 one of us (CRM) inherited a unit where standards of newborn nursing care and record keeping had been consistently high while conscientious medical supetvision had been almost exclusively of a non-interventionist type. Between 1963 and 1971 the unit's consultant and senior nursing staff had not changed, and its policy had changed only in respect of the timing of the first feed. We were therefore able to examine the outcome of infants of very low weight who did not receive "special" or "intensive" care, using the same standards and definitions for live birth, handicap, social class, and gestation-birthweight factors ${ }^{9}$ and the same tests for assessing intelligence and learning difficulties as were used by Jones $e t a l^{10}$ in an analysis of the experience of the neonatal intensive care unit at Hammersmith Hospital, London.

\section{Patients and methods}

Between May 1963 and July 1971, 293 infants weighing 501-1500 g were born in Mansfield and district. All but 57 were delivered in the labour ward of this hospital. Six infants born in the hospital showed only transitory signs of life, but the remainder were admitted to the adjacent baby nursery within three to 20 minutes of birth.

Most mothers had had some antenatal care, but none in premature labour was referred elsewhere. If spontaneous delivery appeared to 
be uncomplicated medical staff were not routinely called to the labour ward. The attending midwife treated birth asphyxia by aspiration of the airways and gave oxygen by face mask without positive-pressure ventilation. Stimulus to the infants' feet, intragastric oxygen, and postural manoeuvre ${ }^{11}$ were also occasionally used. Only 13 infants $(4.4 \%)$ were intubated. One received mouthto-mouth ventilation.

In the nursery minimal handling and disturbance were considered to be paramount. Incubators were used to maintain body temperature (measured rectally by mercury thermometer), the mean rectal temperature during the first 10 days in survivors being $35 \cdot 8 \pm 0.47^{\circ} \mathrm{C}$. Feeds with half-strength, half-cream National Dried Milk were begun when the nursing staff considered it to be prudent and were delivered by intermittent oesophageal gavage ${ }^{12}$ (using rubber tubes). Forty-one infants who were small for gestational age received an appreciably higher mean energy intake/kg body weight $(1.6 \pm \mathrm{SD}$ $0.6 \mathrm{MJ} ; 373 \pm 142 \mathrm{kcal})$ than 90 who were of appropriate weight for gestation $(1 \cdot 2 \pm 0 \cdot 4 \mathrm{MJ} ; 292 \pm 92 \mathrm{kcal})$ during the first seven days. Almost all infants received vitamin $\mathrm{K}$ after birth, three days of intramuscular crystalline penicillin or oral ampicillin in the early neonatal period, a multivitamin preparation after 10 days, and oral iron after three weeks.

Added oxygen was given to 74 of the survivors in concentrations about $5 \%$ more than that required to abolish cyanosis. The average duration of treatment was less than three days, and concentrations of more than $40 \%$ do not seem to have been given to survivors. Inspired oxygen concentrations were only occasionally sampled, however, using a Beckman oxygen analyser. Apnoea monitors were not used. Two infants underwent radiography; blood glucose concentrations were estimated in two and serum bilirubin concentrations in two. Two infants underwent repeated exchange transfusions for rhesus incompatibility and one died elsewhere after referral for an operation for oesophageal atresia. No other investigation was carried out. Apnoeic attacks were treated by the same methods as birth asphyxia.

\section{MINIPRINT TABLES I-III}

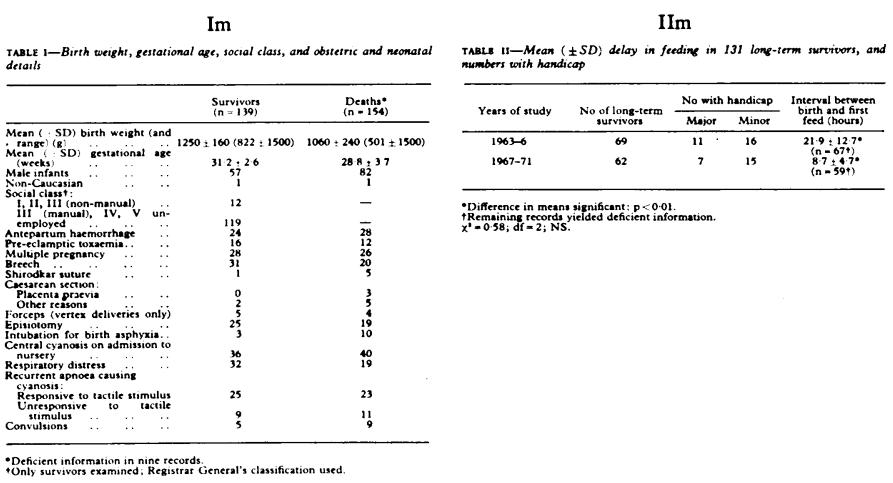

IIIm

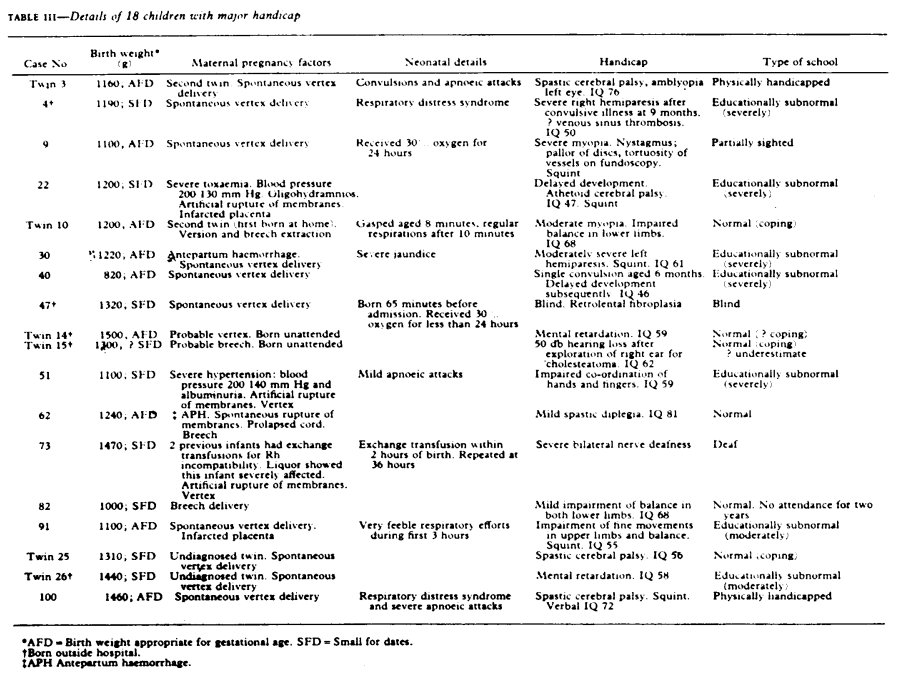

The clinical records indicated the feeds given, the rectal temperature, and the occurrence of respiratory distress, apnoeic attacks, and jaundice. Jaundice was not precisely defined.

There were 137 long-term survivors, who were reviewed between 1977 and 1979. About three-quarters of the parents and children agreed to visit the hospital; the remainder were examined either at home or at school. Two were living abroad but reports were received from them, and four could not be traced although there were medical records of their attendances for review at 12 months of age. Thus, $131(95.6 \%)$ of the survivors were seen. At review the youngest child was aged 6 years 5 months and the oldest 16 years. Clinical examination included a neurological assessment based on a selection of tests scored for age, ${ }^{13}$ a test of visual acuity, and examination of optic fundi without mydriatic. Most of the children had undergone group audiometric testing at their school medical examination, and the results of this were available, together with results of any further tests performed in the hospital ear, nose, and throat department. Pure-tone audiometry had been undertaken when indicated. One hundred and twenty-two children were assessed by intelligence tests (Wechsler) and by the Neale reading analysis, and further information on scholastic achievement was obtained from the children's schoolteachers, who also completed the Rutter behaviour questionnaire. ${ }^{14}$

Respiratory distress was defined as the presence of two of the following features after 4 hours of age, or earlier if death had occurred before that time: grunting respirations, costal recession, and respiratory rate of over 60 per minute. Major handicap was defined as severely impaired intelligence (IQ less than 70), cerebral palsy, or a visual or hearing defect severe enough to require special schooling. Minor handicap was defined as any other neurological abnormality or an IQ between 70 and 84 , or both. Differences in comparisons are reported as significant when the $\chi^{2}$ test for frequencies or the $t$ test for means of normally distributed values yielded $\mathrm{p}<0.05$.

\section{Results}

Table Im gives the birth weights, gestational ages, and obstetric and perinatal details of the neonates who died and the survivors. Of the 154 neonatal deaths, $115(74.7 \%$ ) occurred in the first 24 hours and two $(1.3 \%)$ after the first week. Necropsy was performed on all but 13. Hyaline membrane disease and intraventricular haemorrhage were the most common findings post mortem. One very immature infant and one who underwent exchange transfusion for rhesus incompatibility showed yellow staining of the basal ganglia. Necrotising enterocolitis, heart failure secondary to patent ductus arteriosus, bronchopulmonary dysplasia, hydrocephalus without spina bifida, and milk aspiration were not recorded, though unilateral pneumothorax was found in one intubated infant. Two infants died suddenly and unexpectedly at two and four months of age respectively.

Reports of the two children living abroad suggested that they were physically and intellectually normal. The four untraced children had shown normal development at 12 months of age. The following information refers to the 131 survivors who were examined at school age.

Physical development-At review most of the children without major handicap were of normal physique and appearance. Fourteen were below the third centile for weight $(10$ had been small for gestational age at birth), nine were below the third centile for height (six had been small for dates), and 13 were below the third centile for head circumference (10 small for dates). One child had had an elective operation for a patent ductus arteriosus at 4 years of age, and another had a patent ductus that had not been operated on. Three had had operations on the middle ear.

Handicap-There was no significant difference in the incidence of major and minor handicaps between infants who had been fed early or late after birth (table IIm). Table IIIm gives details of the 18 children who had major handicaps. One child had cicatricial retrolental fibroplasia, but none was considered to have kernicterus. Thirty-one children had minor handicaps, of whom six had minor neurological signs; the other 25 were physically normal but of below average intelligence (IQ 70-84). Further information on these children with minor handicaps is available from us. Fourteen children had a squint, of whom six also had major handicaps. Amblyopia secondary to delayed treatment of the squint was found in five. Three children had sustained hearing defects; of these, two had nerve deafness or mixed conductive and nerve deafness, in one case severe enough to require special schooling.

Intelligence-Table IVm shows the distribution of intelligence quotients as assessed with the Wechsler test of 122 of the children. 
The mean score on the performance scale of infants who were small for gestational age was significantly inferior to that of the infants born with weights appropriate for gestational age. Nineteen of the total sample showed a discrepancy of 15 or more points between verbal and performance scores. The distribution according to social class (figure) serves to emphasise that many of these children were born into disadvantaged families. Nine children were not tested by Wechsler intelligence scale and reading analysis; teachers' reports were available as a basis for the information assembled on them (table $\mathrm{Vm}$ ).

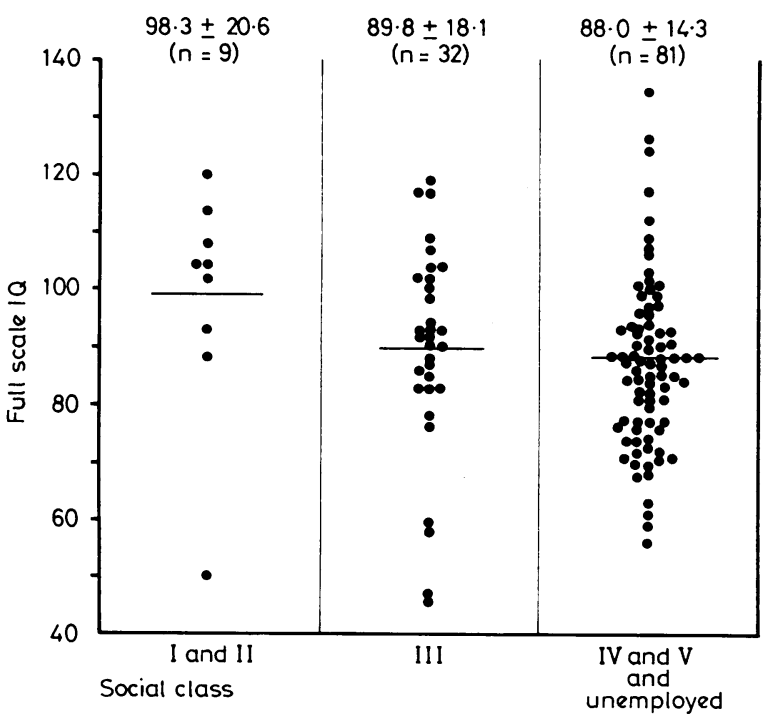

Full scale intelligence quotients (Wechsler test) of children of very low birth weight related to social class. Mean $( \pm S D)$ values also given.

Learning difficulties-Poor reading performance was characteristic of the group as a whole, but no reliable norm was known for the schools of the region. The reading performance of 63 children tested by the Neale reading analysis was two or more years below average, a finding consistent with their verbal intelligence. Ten were nonreaders (IQ range 46-90), and 34 showed three years' reading retardation

MINIPRINT TABLES IV-VI

IVm

\begin{tabular}{|c|c|c|c|c|c|c|c|c|}
\hline \multirow[b]{2}{*}{ Birth weight } & \multicolumn{8}{|c|}{ Inechligeme qüustent } \\
\hline & 55 & $55-69$ & $70-x 4$ & $85-99$ & $1(10 x-114$ & $115-125$ & 125 & Mean 51 \\
\hline 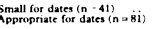 & 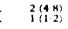 & 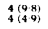 & $\begin{array}{l}7(171) \\
22(2727)\end{array}$ & $\begin{array}{l}17(45) \\
35(432)\end{array}$ & 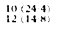 & $\begin{array}{l}1,24 \\
6,84\end{array}$ & 102 & 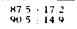 \\
\hline
\end{tabular}

$\mathrm{Vm}$

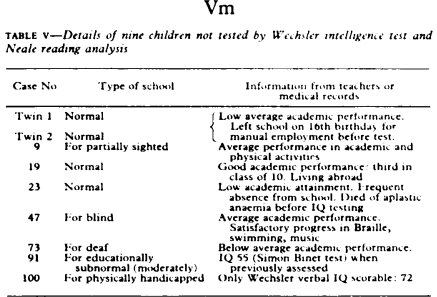

VIm

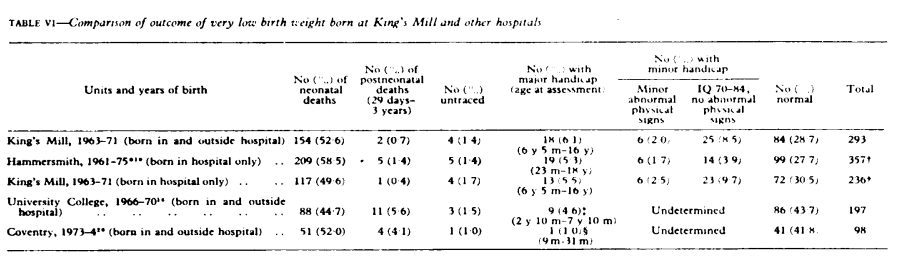

Behaviour-School teachers completed the Rutter behaviour questionnaire for 130 children. Although the questionnaire was not designed for the entire age group in this study, it documents teachers' perceptions on such factors as overactivity, abnormal muscular movements, anxiety, unjustifiable absence from school, attention span, sphincter control, and stammering or other speech defect. No specific undesirable pattern of behaviour, emotional disturbance, or neurosis was apparent. Maladjustment was not reported. Teachers from many different schools, however, indicated that poor concentration and attention span were present in 48 and distinctive features in 35. This problem is thus perhaps nine times more common in children of very low birth weight than in British children of all birth weights, ${ }^{15}$ presenting either as an isolated disability or compounding other handicaps.

\section{Discussion}

To compare the results of the Mansfield births with those of other centres we reviewed reports in which live birth was defined in a comparable way and $95 \%$ or more survivors were examined ${ }^{1016-20}$ (and P A Davies, personal communication on Hammersmith Hospital data, 1979). We also attempted to classify and compare morbidity (reported in various ways) according to other previously defined criteria. ${ }^{618}{ }^{21}$ Although the Mansfield children rarely received neonatal medical intervention, such comparison shows that their rates of neonatal survival and postneonatal death were favourable, the proportion with major handicap was similar to that in children born in other centres, and differences in the incidences of retrolental fibroplasia and hearing defect were negligible. Only the Hammersmith Hospital analysis, ${ }^{10}$ however, attempted to assess the impact of neonatal intensive care on a community-derived cohort of children of very low birth weight at school age. Table VIm compares the outcome in the different centres.

Neonatal mortality was higher (though not significantly so) in infants born at King's Mill Hospital than in those born at University College Hospital, London. The mortality at King's Mill Hospital, however, was significantly lower than that in infants born in the Hammersmith Hospital for the birthweight group as a whole and also for those of $1000 \mathrm{~g}$ or less. Nevertheless, despite increased medical staffing, neonatal intervention, and referral of some infants for respiratory support to "good units," there was no appreciable improvement in the neonatal mortality at King's Mill Hospital during the years after the study period (table VII).

We made no attempt to establish causal factors for differences in neonatal mortality nor can we say how much better (or worse) the Mansfield results might have been had the infants been

TABLE VII-Neonatal mortality of infants weighing $501-1500 \mathrm{~g}$ at birth compared between hospitals

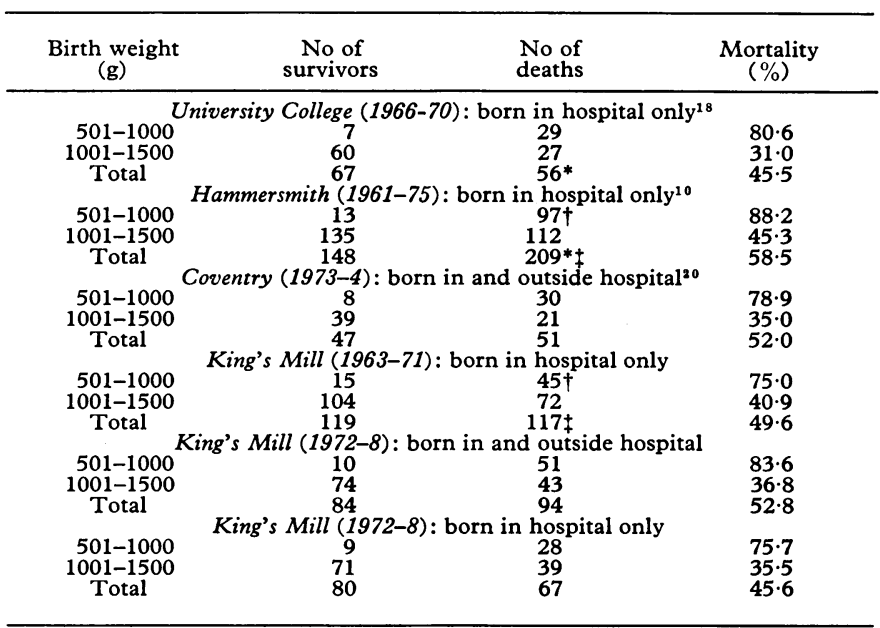

${ }^{*} \chi^{2}=6.2, \mathrm{p}<0.02 . \quad \dagger \chi^{2}=4.8, \mathrm{p}<0.05 . \quad \ddagger \chi^{2}=4.6, \mathrm{p}<0.05$ 
delivered and reared differently or elsewhere. No authoritative information yet exists linking social class and neonatal mortality for children of very low birth weight, as exists for total births. ${ }^{22}$

In whichever of three ways major handicap is defined the outstanding point is the smallness of the difference in outcome between the two London neonatal units using intensive care methods and the Mansfield unit, which relied entirely on nursing judgments and procedures.

The proportion of Mansfield children with minor nervoussystem signs differed little from that of the Hammersmith sample, and we consider it to be unlikely therefore that the neonatal nursing techniques prejudiced the children's later performance, even when starvation during the first 24 hours was practised. ${ }^{23}$ Minor handicap defined as slow learner status (IQ 70-84) without nervous-system signs was more common and commensurate with the excessive number of Mansfield children born to parents of manual occupational class. Mean full scale intelligence quotients of the Mansfield children, however, did not differ significantly from those of a sample of children reared at Hammersmith Hospital when compared according to occupational class, nor when the survivors who had weighed $1000 \mathrm{~g}$ or less were compared. (Tabulated details are available from us as an appendix.) A discrepancy of 15 or more points between verbal and performance scores was no more common in the Mansfield than the Hammersmith sample. Learning difficulties were commonplace in both groups, though direct comparison is not valid.

Broadly, we think that educational attainment and social-class factors in the Mansfield children of very low birth weight closely parallel the findings in the $6.2 \%$ of socially disadvantaged British children of all birth weights. ${ }^{24}$ We find it difficult, therefore, to escape the conclusion that scientific and highly skilled medical intervention in the years under discussion made little impact on the outcome for infants of very low birth weight. The results in Mansfield were achieved by using well-qualified nurses as supervisors with experienced but unqualified nurses helping, using a minimum of simple equipment, and by a few staff members getting to know the parents well; this combination is as readily found in some remote mission hospitals as in prestigious teaching institutions.

The study was supported by a grant from the Spastics Society, and the Mansfield Hospitals' League of Friends helped some of the families with travelling expenses. We thank Mrs M P Hind and her health visitor colleagues and $\mathrm{Mr}$ G A Hall, records officer, for their help in tracing the children. We wish to thank the children, parents, and teachers for their co-operation in the project. Dr J C G Pearson gave statistical help, and Professor D Hull gave valuable criticism. Dr Pamela Davies generously provided unpublished information from Hammersmith Hospital. We thank Miss K Reed for secretarial help. Necropsies were performed by Dr A MacFarlane. We pay tribute to Sister Turner and her staff in the special-care baby unit for their consistent devotion and skills. The children were reared under the supervision of the late Dr A C Blandy and Dr J S Fitzsimmons.

\section{Correspondence should be addressed to Dr C R Maddock.}

\section{References}

${ }^{1}$ Alberman E. Stillbirths and neonatal mortality in England and Wales by birthweight, 1953-71. Health Trends 1974;6:14-7.

2 Douglas JWB, Gear R. Children of low birthweight in the 1946 national cohort: behaviour and educational achievement in adolescence. Arch Dis Child 1976;51:820-7.

${ }^{3}$ Davies PA. Outlook for the low birth weight baby-then and now. Arch Dis Child 1976;51:817-9.

${ }^{4}$ Hughes-Davies TH. Conservative care of the newborn baby. Arch Dis Child 1979;54:59-61.

${ }^{5}$ Schlesinger ER. Neonatal intensive care: planning for services and outcomes following care. $\mathcal{F}$ Pediatr 1973;82:916-20.

${ }^{6}$ Stewart AL. The survival of low birth weight infants. Br $\mathcal{F}$ Hosp Med $1977 ; 18: 182-90$.

${ }^{7}$ Anonymous. Caring for babies of very low birth weight. $\mathrm{Br}$ Med $\mathcal{F} 1978$; ii:1105-6.
${ }^{8}$ Working Party on the prevention of early neonatal mortality and morbidity. Report, London: Department of Health and Social Security, 1974.

9 Davies PA, Robinson RJ, Scopes JW, Tizard JPM, Wigglesworth JS. Medical care of newborn babies. London: Heinemann, 1972:323. (Clinics in Developmental Medicine Nos 44/45.)

${ }^{10}$ Jones RAK, Cummins M, Davies PA. Infants of very low birth weight: a 15 year analysis. Lancet 1979 ;i:1332-5.

${ }^{11}$ Corner B. Prematurity - the diagnosis, care and disorders of the premature infant. London: Cassell, 1960:391.

${ }_{12}$ Corner B. Prematurity-the diagnosis, care and disorders of the premature infant. London: Cassell, 1960:260.

13 Touwen BCL, Prechtl HFR. The neurological examination of the child with minor nervous dysfunction. London: Heinemann, 1970. (Clinics in Developmental Medicine No 38.)

${ }^{14}$ Rutter M. A children's behaviour questionnaire for completion by teachers. F Child Psychol Psychiatry 1967;8:1-11.

${ }^{15}$ Fogelman K. Britain's sixteen-year-olds. London: National Children's Bureau, 1976:17.

${ }^{16}$ Francis-Williams J, Davies PA. Very low birth weight and later intelligence. Dev Med Child Neurol 1974;16:709-28.

17 Davies PA, Tizard JPM. Very low birthweight and subsequent neurological defect. Dev Med Child Neurol 1975;17:3-17.

${ }^{18}$ Stewart AL, Reynolds EOR. Improved prognosis for infants of very low birthweight. Pediatrics 1974;54:724-35.

${ }^{19}$ Stewart A, Turcan D, Rawlings G, Hart S, Gregory S. Outcome for infants at high risk of major handicap. In: Elliott $\mathrm{K}$ and $\mathrm{O}^{\prime}$ Connor $\mathrm{M}$ eds. Major mental handicap: methods and costs of prevention. Elsevier/ Excerpta Medica/North Holland, 1978:151-71. (Ciba Foundation Symposium 59.)

${ }^{20}$ Hommers M, Kendall AC. The prognosis of the very low birth weight infant. Dev Med Child Neurol 1976;18:745-52.

${ }^{21}$ Davies PA. Infants of very low birth weight. An appraisal of some aspects of their present neonatal care and of their later progress. In: Hull D, ed. Recent advances in paediatrics. No 5. London: Churchill Livingstone, 1976:89-128.

${ }^{22}$ Chamberlain G, Phillip E, Howlett B, Masters K. British births 1970. Vol 2. Obstetric care. London: Heinemann, 1978:258.

${ }^{23}$ Davies DP. The first feed of low birth weight infants: changing attitudes in the twentieth century. Arch Dis Child 1978;53:187-92.

${ }^{24}$ Wedge P, Prosser H. Born to fail ? London: Arrow in association with National Children's Bureau, 1973:45-58.

(Accepted 25 September 1980)

ONE HUNDRED YEARS AGO Medical witnesses, it is well known, have often considerable difficulty in obtaining remuneration for a compulsory attendance and evidence on trials for murder. The sum allowed by the county is rarely adequate to cover the expenses incurred by a necessary residence in a town during the assizes. It is in the power of a judge to order the payment of a sum beyond the tariff to a medical witness; but this power is seldom exercised for the benefit of the profession; and it is extremely rare that a judge, in the absence of any special application by counsel, will of his own accord order additional fees to be paid. It is, therefore, with great satisfaction that we notice, in reference to the trial and conviction of three persons on a charge of murder, which has just taken place at the Lincoln Assizes, that the new judge (Mr Justice Stephen) has set a good example in this respect. The principal medical witness in this case was $\mathrm{Dr} H \mathrm{~T}$ Stiles of Spalding; and his evidence was considered so satisfactory that the learned judge, "in recognition of the care taken by that gentleman in the post mortem examination, and the ability he displayed in giving his evidence, made an order on Her Majesty's Treasury that a special fee of five guineas, over and above the ordinary allowance, be granted him as a witness." Referring to the reported evidence of Dr H Stiles, we consider the commendation of the learned judge to be well merited. The medical evidence clearly proved that the deceased had died from suffocation. There was a fracture of two ribs on the right side, with other signs of violent compression of the chest, rendering it probable that one or other of the prisoners had caused suffocation by sitting or kneeling forcibly on the chest of the deceased. There was evidence of heart-disease, which might have accelerated death. There was one remarkable circumstance in the case which tended to indicate sudden death from violence. When the dead body was found, the deceased held in his right hand a door-key, tightly clenched. It was shown that the female prisoner, who was housekeeper to deceased, had gone off with this key, and the deceased, in going after her in order to obtain it, was waylaid by the two male prisoners, and met with his death in the manner described. This, with other circumstances, connected the woman with the act. The prisoners were convicted of murder; but the jury found that their intention was to commit robbery, and that they had not contemplated the death of the deceased. (British Medical fournal, 1880.) 